\title{
Review \\ Pro/con debate: Do the benefits of regionalized critical care delivery outweigh the risks of interfacility patient transport?
}

Jeffrey M Singh ${ }^{1,2}$ and Russell D MacDonald 2,3

\author{
1 Interdepartmental Division of Critical Care and Department of Medicine, University of Toronto, Toronto Western Hospital, 399 Bathurst Street, \\ 2 McLaughlin - 411K, Toronto, Ontario M5T 2S8, Canada \\ ${ }^{2}$ Research and Development, Ornge Transport Medicine,20 Carlson Court, Suite 400, Toronto, Ontario M9W 7K6, Canada \\ 3Division of Emergency Medicine, Department of Medicine, University of Toronto, 2075 Bayview Avenue, Room C-710, Toronto, Ontario M4N 3M5 \\ Canada
}

Corresponding author: Jeffrey M Singh, jeff.singh@uhn.on.ca

Published: 10 August 2009

This article is online at http://ccforum.com/content/13/4/219

(c) 2009 BioMed Central Ltd
Critical Care 2009, 13:219 (doi:10.1186/cc7883)

institutions, however, and the projected benefits of concentrating care must be weighed against the risks and costs of patient transport as well as the ensuing potential barriers to longitudinal care.

You are providing input in planning for critical care services to large regional health authority. You are considering concentrating some critical care services into high-volume regional centres of excellence, as has been done in other fields of medicine. In your region, this would require several centres with differing levels of expertise that are geographically separated. Given there are inherent risks and time delays associated with interfacility patient transport, you debate whether these potential risks outweigh the benefits of regional centres of excellence.

\section{Introduction}

Critical care is a highly complex, expensive and resourceintensive dimension of the healthcare system [1], and the demand for these services is expected to grow due to the aging population [2,3]. Regionalization of critical care services has received much attention as a strategy to improve patient outcomes and to realize efficiencies in care delivery [4-7]. Regionalization entails the allocation of scarce healthcare resources on the basis of geography, and has been implemented in other areas of medicine including trauma, paediatrics and neonatal care. Regionalized delivery of critical care would create a tiered system of critical care units where a designated number of high-volume specialty referral centres would accept patients in transfer [5]. Patients who require services not available locally or who require a higher level of care than is provided at their local institution would be transported to such a specialty centre.

Proponents claim that regionalization improves outcomes, citing literature demonstrating a positive relationship between case volumes and outcomes [8-13]. Regionalization may also reduce costs by reducing duplication of expensive infrastructure and resources [14]. Restricting healthcare services this way forces the movement of patients between healthcare
In the present debate we shall explore the advantages and disadvantages of the strategy of restricting critical care services to a limited number of facilities with high case volume (regionalized critical care). We also focus on an important but often neglected aspect of regionalization - the requirement for and the impact of patient transport outside the critical care setting in order to provide access to regionalized healthcare resources.

\section{Pro - regionalization of critical care will improve patient outcomes and care delivery}

Proponents of regionalization contend that concentration of specialty or resource-intensive services may lead to improvements in patient care and cost-savings. Potential benefits of regionalization may include a reduction in practice variation with improved adherence to best practices, improved procedural outcomes due to higher provider skill and experience in high-volume centres, and a concentration of expertise and resources that reduces duplication of infrastructure, may increase efficiency of care delivery and allows for savings due to economies of scale.

\section{Regionalization will improve patient care}

There is little direct evidence that regionalizing critical care services leads to improvements in patient outcomes compared with a more decentralized system. There are, however, data to suggest that variation in critical care practices and healthcare costs may be reduced through regionalization, and that patients who are cared for in high-volume centres may

$\mathrm{ICU}=$ intensive care unit. 
have improved outcomes compared with those treated in lower-volume centres.

Wide variations in practice have been observed in the delivery and practice of critical care, including practices that are linked to patient outcomes (including venous thromboembolism prophylaxis $[15,16]$, strategies to reduce ventilatorassociated pneumonia [17], central venous catheter care [18] and intensivist physician staffing $[19,20])$. Regionalization of critical care may reduce practice variation by concentrating care into fewer centres with highly-skilled staff and improved implementation of best-practices [21], with a resulting improvement in patient outcomes.

In addition to reducing system-level or hospital-level variability in practice, regionalization may also improve patient care by concentrating patients at centres where providers treat a large number of similar cases. Although previous studies evaluating the relationship between case volume and outcome in critical care have produced conflicting results [8-13,22], positive volume-outcome relationships have been reported in critically ill patients [13], including those with sepsis [12] and those requiring mechanical ventilation [11]. These positive relationships have also been observed in the delivery of healthcare for other acute illnesses, including trauma [23], cardiac revascularization [24] and subarachnoid haemorrhage [25]. One retrospective study observed a significant reduction in mortality when patients with traumatic injuries were transported from nontertiary emergency departments to major trauma centres, even after accounting for the nonrandom transport of patients [26]. In most instances these associations have been observed where there is already regionalized care delivery; there are no before-after studies in critical care demonstrating the benefit of this strategy where regionalization is not already in place. There is one recent study that attempted to estimate the impact of regionalizing the provision of mechanical ventilation, which estimated a substantial benefit if patients who required mechanical ventilation and were cared for in low-volume hospitals were instead transported to high-volume hospitals [27].

There are possible limitations to the data on volume-outcome relationships. The association of higher case volumes and improved outcomes is frequently attributed to the principle of practice makes perfect, where skills and processes are optimized by repetition. Some authors, however, have speculated this association may be the result of residual confounding [28-30]. In the United States, where much of the supporting data have originated, patients may be selectively referred to institutions with better outcomes (that is, high volumes are a result of patients selecting institutions with good care, and good outcomes are not causally related to high volumes) [28]. In contrast, volume outcome data have been conflicting in the single-payer publicly funded Canadian healthcare system, where patient referral is less discretionary $[31,32]$. Finally, some critics have suggested that these relationships may be explained in part by patient-level variables that were not adequately controlled for or adjusted for, noting that patient-level factors have been found to be far more important than institutional case volumes in mortality after complex surgery [29], and improvements in mortality have also been observed in coronary artery bypass grafting despite decreasing case volumes [30].

In summary, there are data to suggest that critically ill patients who are cared for at higher-volume centres may have improved outcomes. We must acknowledge that there are no definitive data demonstrating that regionalization of critical care delivery will result in benefit, and the existing data have limitations. Nevertheless, multiple studies in varied subgroups of critically ill patients and acutely ill patients have observed positive volume-outcome relationships, and it is possible that regionalization of critical care delivery in noncentralized jurisdictions may realize these benefits.

\section{Regionalization may reduce costs}

Regionalization may improve efficiency in the delivery of healthcare by reducing duplication of costly and scarce resources and infrastructure, as well as improving economies through higher case volumes and improved efficiency and economies of scale (cost advantages derived from advantageous purchasing, managerial and financial practices with increased case volumes). One British study found that larger intensive care units (ICUs) (as measured by the number of beds) were associated with lower total costs, lower staffing costs and lower consumable costs per patient-day [14]. Regionalization strategies may also be cost-effective in cardiac surgery [33], in joint replacement [34] and in subarachnoid haemorrhage [35], although these estimates may be sensitive to the predicted mortality benefit of high-volume centres and the assumption of a low risk of transport-related mortality. It is important to note that, even in the absence of clear data demonstrating efficacy, some ancillary services that may be required by critically ill patients - such as renal replacement therapy, neurosurgery and cardiac angiography and intervention - are already regionalized to some degree in most jurisdictions for practical reasons (primarily the high cost of specialized equipment and human resources).

\section{Con - risks of transport and impact on transferring hospitals and patients may outweigh benefits of regionalization}

Regionalization may have negative impact on care delivery, which should be balanced against any potential benefits. These potential disadvantages can be broadly categorized into factors related to the transport of patients to high-volume referral centres and factors related to the impact of regionalization on the function and staffing of lower-volume centres.

\section{Risks associated with patient transport}

Identification of the critically ill patient and secondary transport The appropriate prehospital triage of critically ill patients and their referral to the appropriate healthcare facility are 
dependent on the rapid and accurate identification of their diagnoses and healthcare needs. Although straightforward in some subgroups of critically ill patients, such as in those with traumatic injuries, it can be very difficult to determine what resources will be required for other patients with less defined pathology, such as those with undifferentiated hypoxic respiratory failure, making primary referral to specialty critical care centres difficult, and perhaps necessitating the secondary transport of patients after their initial assessment or admission to a low-volume centre. It should be noted that a significant proportion of patients admitted to the ICU, however, are admitted from the local emergency department $[36,37]$. These patients could instead be transported directly to a high-volume referral facility if they are identified early. Some patients may develop new problems requiring specialized services (that is, acute respiratory distress syndrome, sepsis, renal failure) while in hospital, however, necessitating an interfacility transport. As the degree of regionalization increases, we expect there to be an increased demand for secondary interfacility transport.

Critically ill patients may face increased risk outside the ICU Critically ill patients may be at risk of clinical deterioration due to the stresses of transport, due to progression of their underlying disease or due to adverse events related to clinical care occurring before or during transport. Communication is the single leading source of adverse events and errors in healthcare [38-40], as well as in the transport setting [41], and patient transports increase the number of patient handovers that may contribute to communication errors. The one study that estimated a benefit of regionalizing care of patients requiring mechanical ventilation did not take into account the potential risks of treatment delays or adverse events related to the transportation of patients to high-volume specialty centres [27]. Admittedly, the attributable risk of interfacility transport of critically ill patients is not well defined: the majority of published data evaluating the safety of out-ofhospital transport of critically ill patients are retrospective series or small, prospective series without comparison groups or controls [42-48]. Many studies did not report adverse events occurring in transit and do not typically include transport-associated or vehicle-associated events. There is insufficient high-quality information to meta-analyse or give substantive conclusions of the rate of clinical adverse events during out-of-hospital transport [49].

There are data regarding critical events during transport, including clinical deteriorations as well as near misses, or events that could have potentially caused harm. One study of a large Canadian transport agency determined that the rates of critical events and of events leading to potential patient harm were $1.15 \%$ and $0.2 \%$ of all transports, respectively [41]. In acutely ill patients, serious in-transit critical events were found in approximately $5 \%$ of all nonelective air medical transports [50], and $5.6 \%$ of patients with acute coronary syndrome or cardiogenic shock undergoing interfacility patient transfer experience a critical event [51]. These data are consistent with observed incidents during transport of patients within the hospital (intrafacility transport), where the incidence of adverse events during transport outside the ICU has been estimated to be between 5.5\% and 6.6\% [52-54].

It is important to acknowledge that critically ill patients, by nature of their physiological instability, may clinically deteriorate even if they remain in the ICU, and it is important to compare the incidence of adverse events during transport against the baseline incidence of adverse events in the ICU. There are observational data suggesting that transport of patients outside the ICU setting may carry increased risk: one study found that $43 \%$ of medical errors in ICU patients occurred when they were outside the ICU [55], and the incidence of adverse events and critical events in patients undergoing intrahospital transport $[54,56,57]$ is consistently higher than the incident rate of adverse events documented in the ICU [58,59]. There are no comparative studies, however, evaluating outcomes or adverse event rates in patients who are either transported or not transported.

Vehicular and occupational risks associated with transporting patients

The role and safety of emergency medical aircraft became the subject of public debate in the United States following several high-profile aircraft crashes in 2008 and a recent review by a national governing body [60]. Although the overall accident rate for emergency medical aircraft is low and varies substantially across jurisdictions, some operators have exemplary safety records while some operators have accident rates much higher than civilian aircraft carriers [61-63]. The hazard of vehicle accidents is not limited to aircraft: the available data suggest land ambulance accidents are a cause of healthcare worker and patient mortality [64,65] and occur with sufficient frequency that emergency medical personnel have a similar occupational risk of death as firefighters and police [65].

In summary, the actual health impact and risk of transportation of critically ill patients is not precisely known. The existing data evaluating adverse events and critical events would suggest that this risk is low, although it is probably greater than the risk of deterioration experienced by patients in an ICU. Although low, any marginal increase in risk and any negative impact on patient health should be considered in health policy planning through which increased regionalization will result in increased interfacility patient transport.

\section{Potential negative effects of regionalization on lower-volume centres}

Critical care plays a key role in supporting multiple other disciplines within a hospital (that is, surgery, emergency medicine, anaesthesia, internal medicine, and so forth) and critically ill patients are admitted to the ICU from a number of sources (hospital ward, emergency room, operating theatre, 
and so forth). The potential impact of regionalizing critical care on low-volume centres is greater than when regionalizing other specialty services such as coronary revascularization because the restriction of ICU beds may negatively impact on other hospital services.

Regionalization of critical care may have other negative effects on healthcare delivery that have not been well quantified, although one recent qualitative study identified multiple barriers to the acceptance and implementation of regionalization strategies [66]. The movement of patients to high-volume centres removes patients from their local support networks. This may add to the emotional stress endured by families as well as creating a geographical obstacle for the provision of longitudinal care, rehabilitation and chronic disease management following critical illness. Patients from remote areas may also feel a sense of depersonalization when transferred to large, high-volume hospitals.

At an institutional level, the regionalization of specialty services may lead to a reduction in available specialists for patients in peripheral communities, as specialists are moved to high-volume centres. The removal of specialty programmes from hospitals may also lead to an erosion of staff morale and pride, and there has been a documented decrease in job satisfaction and staff morale during similar reallocations in the merger of healthcare institutions [67]. Stakeholders have also expressed concern regarding the financial implications of the diversion of patients away from low-volume institutions [66]. Although it is difficult to quantify or predict the impact of these phenomena, the effects of regionalization on lowvolume centres should not be underestimated, both in terms of care delivery and the effect on healthcare workers.

Finally, because the exact mechanisms through which patients in high-volume centres experience benefit are not known, further research to elucidate these factors would be invaluable especially if some of these factors could be applied in the setting of a lower-volume centre to improve patient outcomes.

\section{Impact of underlying geography and demographics on regionalization}

One of the key factors that will determine the efficacy of critical care regionalization will be the local geography and population demographics. Although some effects of regionalization are fixed regardless of geography (that is, the benefit of high-volume centre care, or the negative effect of removing resources from smaller, low-volume centres), the risk of patient transport may be related, at least in part, to the duration of a patient's exposure to the out-of-hospital environment [68]. The risks of transport may consequently erode the potential benefits of regionalization in areas in which transport durations are long. Conversely, in population-dense areas in which patients are transported short distances, the benefits of regionalization may outweigh the small risks related to brief patient transports between sites. In the modelling study by
Khan and colleagues that estimated a benefit if mechanical ventilation was regionalized, it is interesting that the median distance patients required to travel to reach a high-volume centre was only 13.6 kilometres [27]. Additionally, most of the estimated benefit was seen in urban areas where the distance between the centres is probably small.

As referral centres become more geographically distant and subtend a larger area, the transport distances and times increase proportionately. As an example, one study evaluating the potential of regionalizing high-risk specialized surgeries in the United States found that aggressive regionalization would result in $80 \%$ of patients changing centres, increasing the travel time for more than $50 \%$ of these patients by greater than 60 minutes [69]. Finally, the costs involved in establishing a cohesive transport system across a large geographic jurisdiction can be very high and should be weighed against the clinical benefits and potential cost-savings of regionalization.

The effect of geography may underlie observations from Canada, where urban, population-dense areas are often separated by vast expanses. The median transport distance for critically ill patients undergoing interfacility transport in Canada is almost 10 times further than that in the United States $[50,70,71]$. Canadian studies have demonstrated that regionalization in urban settings resulted in gains of efficiency and health outcomes, but these gains were not clear in rural settings where access to services was more restricted $[72,73]$.

The underlying geography will also determine the specific resources required for patient transport. In population-dense areas where transport distances are likely to be short, landbased critical care transport teams may suffice. For larger jurisdictions, an organized and well-integrated system of air and land ambulances may be required. Although air ambulances are more expensive to purchase and maintain and more complex to administer than land ambulances, their greater speed and range make them an invaluable resource in large jurisdictions, especially where there is limited road access or where traffic congestion extends response times by land ambulances. Transport crews, regardless of their makeup and medical background, should be competent to manage critically ill patients and should be familiar with the specialized transport environment.

These examples underscore the potential impact of geography on both the implementation and outcomes of regionalization schemes, and it would be important to consider local geography when planning regionalized healthcare delivery systems.

\section{Conclusions and recommendations}

There are both advantages and disadvantages regarding regionalization. These pros and cons must be weighed 
carefully in the specific geographic, population and administrative context in which a strategy of regionalized critical care delivery is being considered. Providing a generalized response to the scenario presented in the introduction to the current review is difficult, although we will provide our own framework for addressing the relevant issues.

Firstly, despite widespread interest in the regionalization of critical care, the benefits of this approach remain controversial. Some of this controvery may stem from the belief that observed volume-outcome relationships are not generalizable across different healthcare delivery systems and jurisdictions. Whether regionalizing the delivery of critical care in a decentralized (that is, non-regionalized or less regionalized) healthcare system will necessarily bring with it improvements in care and increased adherence to best practices, and whether these marginal improvements will outweigh the additional risks imposed by patient transport, is unclear. Nevertheless, there are compelling data from a broad base of associated acute care medical fields in which highercase-volume institutions have superior patient outcomes.

Secondly, an organized transport system is essential to ensure that patients can access these resources in a safe and timely manner. Although the makeup and structure of such a system will vary according to the local landscape and geography, any strategy to regionalize critical care must include an organized mechanism to move patients to and between healthcare institutions. If not, regionalization of critical care effectively becomes the geographic restriction of critical care. The specific makeup of these transport systems with respect to vehicles and crews will depend largely on the underlying geography, demographics and transport demand of each jurisdiction.

Consideration must also be given to which services should be regionalized. Given the scarcity and expense of resources and given the existing data on volume-outcome relationships, the regionalization of specialty programmes (that is, trauma, neurosurgery, neonatal care) is reasonable. Patients requiring these services can be identified early and the care of these patients often requires significant other specialized human and healthcare resources. Absolute regionalization of all critical care services, however, is unlikely to be desirable due to the aforementioned interdependence of hospital medical and surgical ICUs.

In conclusion, regionalization is best supported and most easily implemented in urban or population-dense areas where patients have minimal incremental transport requirements to access definitive care at a high-volume centre. Healthcare systems covering very large regions may require some degree of regionalization because it is not practical or desirable to build a large number of full-service specialty hospitals, although the aforementioned considerations may still be relevant in determining the extent of regionalization and size and location of referral centres.

\section{Competing interests}

The authors declare that they have no competing interests.

\section{Authors' contributions}

JMS and RDM together conceived the idea, and drafted and revised the manuscript.

\section{References}

1. Halpern NA, Pastores SM, Greenstein RJ: Critical care medicine in the United States 1985-2000: an analysis of bed numbers, use, and costs. Crit Care Med 2004, 32:1 254-1259.

2. Angus DC, Kelley MA, Schmitz RJ, White A, Popovich J, Jr: Caring for the critically ill patient. Current and projected workforce requirements for care of the critically ill and patients with pulmonary disease: can we meet the requirements of an aging population? JAMA 2000, 284:2762-2770.

3. Needham DM, Bronskill SE, Calinawan JR, Sibbald WJ, Pronovost PJ, Laupacis A: Projected incidence of mechanical ventilation in Ontario to 2026: preparing for the aging baby boomers. Crit Care Med 2005, 33:574-579.

4. Thompson DR, Clemmer TP, Applefeld JJ, Crippen DW, Jastremski MS, Lucas CE, Pollack MM, Wedel SK: Regionalization of critical care medicine: task force report of the American College of Critical Care Medicine. Crit Care Med 1994, 22: 1306-1313.

5. Barnato AE, Kahn JM, Rubenfeld GD, McCauley K, Fontaine D, Frassica JJ, Hubmayr R, Jacobi J, Brower RG, Chalfin D, Sibbald W, Asch DA, Kelley M, Angus DC: Prioritizing the organization and management of intensive care services in the United States: the PrOMIS Conference. Crit Care Med 2007, 35:10031011

6. Angus DC, Black N: Improving care of the critically ill: institutional and health-care system approaches. Lancet 2004, 363: 1314-1320.

7. Kelley MA, Angus D, Chalfin DB, Crandall ED, Ingbar D, Johanson W, Medina J, Sessler CN, Vender JS: The critical care crisis in the United States: a report from the profession. Chest 2004, 125:1514-1517.

8. Jones J, Rowan $\mathrm{K}$ : Is there a relationship between the volume of work carried out in intensive care and its outcome? Int J Technol Assess Health Care 1995, 11:762-769.

9. Durairaj L, Torner JC, Chrischilles EA, Vaughan Sarrazin MS, Yankey J, Rosenthal GE: Hospital volume-outcome relationships among medical admissions to ICUs. Chest 2005, 128: 1682-1689.

10. lapichino G, Gattinoni L, Radrizzani D, Simini B, Bertolini G, Ferla L, Mistraletti G, Porta F, Miranda DR: Volume of activity and occupancy rate in intensive care units. Association with mortality. Intensive Care Med 2004, 30:290-297.

11. Kahn JM, Goss CH, Heagerty PJ, Kramer AA, O'Brien CR, Rubenfeld GD: Hospital volume and the outcomes of mechanical ventilation. $N$ Engl J Med 2006, 355:41-50.

12. Peelen L, de Keizer N, Peek N, Scheffer G, van der Voort P, de Jonge $E$ : The influence of volume and intensive care unit organization on hospital mortality in patients admitted with severe sepsis: a retrospective multicentre cohort study. Crit Care 2007, 11:R40.

13. Glance LG, Li Y, Osler TM, Dick A, Mukamel DB: Impact of patient volume on the mortality rate of adult intensive care unit patients. Crit Care Med 2006, 34:1925-1934.

14. Jacobs P, Rapoport J, Edbrooke D: Economies of scale in British intensive care units and combined intensive care/high dependency units. Intensive Care Med 2004, 30:660-664.

15. Cook D, McMullin J, Hodder R, Heule M, Pinilla J, Dodek P Stewart T: Prevention and diagnosis of venous thromboembolism in critically ill patients: a Canadian survey. Crit Care 2001, 5:336-342.

16. Imberti D, Ageno W: A survey of thromboprophylaxis management in patients with major trauma. Pathophysiol Haemost Thromb 2005, 34:249-254.

17. Kahn JM, Rubenfeld GD: Translating evidence into practice in the intensive care unit: the need for a systems-based approach. J Crit Care 2005, 20:204-206.

18. Rickard CM, Courtney M, Webster J: Central venous catheters: a survey of ICU practices. J Adv Nurs 2004, 48:247-256. 
19. Brilli RJ, Spevetz A, Branson RD, Campbell GM, Cohen H, Dasta JF, Harvey MA, Kelley MA, Kelly KM, Rudis MI, St Andre AC, Stone JR, Teres D, Weled BJ: Critical care delivery in the intensive care unit: defining clinical roles and the best practice model. Crit Care Med 2001, 29:2007-2019.

20. Angus DC, Shorr AF, White A, Dremsizov TT, Schmitz RJ, Kelley MA: Critical care delivery in the United States: distribution of services and compliance with Leapfrog recommendations. Crit Care Med 2006, 34:1016-1024.

21. Kahn JM, Angus DC: Reducing the cost of critical care: new challenges, new solutions. Am J Respir Crit Care Med 2006, 174:1167-1168.

22. Needham DM, Bronskill SE, Rothwell DM, Sibbald WJ, Pronovost PJ, Laupacis A, Stukel TA: Hospital volume and mortality for mechanical ventilation of medical and surgical patients: a population-based analysis using administrative data. Crit Care Med 2006, 34:2349-2354.

23. Nathens AB, Jurkovich GJ, Maier RV, Grossman DC, Mackenzie EJ, Moore M, Rivara FP: Relationship between trauma center volume and outcomes. JAMA 2001, 285:1164-1171.

24. Brown DL: Analysis of the institutional volume-outcome relations for balloon angioplasty and stenting in the stent era in California. Am Heart J 2003, 146:1071-1076.

25. Bardach NS, Zhao S, Gress DR, Lawton MT, Johnston SC: Association between subarachnoid hemorrhage outcomes and number of cases treated at California hospitals. Stroke 2002, 33:1851-1856.

26. Newgard CD, McConnell KJ, Hedges JR, Mullins RJ: The benefit of higher level of care transfer of injured patients from nontertiary hospital emergency departments. J Trauma 2007, 63: 965-971.

27. Kahn JM, Linde-Zwirble WT, Wunsch $H$, Barnato AE, Iwashyna TJ, Roberts MS, Lave JR, Angus DC: Potential value of regionalized intensive care for mechanically ventilated medical patients. Am J Respir Crit Care Med 2008, 177:285-291.

28. Luft HS, Hunt SS, Maerki SC: The volume-outcome relationship: practice-makes-perfect or selective-referral patterns? Health Serv Res 1987, 22:157-182.

29. Rodgers M, Jobe BA, O'Rourke RW, Sheppard B, Diggs B, Hunter JG: Case volume as a predictor of inpatient mortality after esophagectomy. Arch Surg 2007, 142:829-839.

30. Ricciardi R, Virnig BA, Ogilvie JW, Jr, Dahlberg PS, Selker HP, Baxter NN: Volume-outcome relationship for coronary artery bypass grafting in an era of decreasing volume. Arch Surg 2008, 143:338-344.

31. Cantor WJ, Hall R, Tu JV: Do operator volumes relate to clinical outcomes after percutaneous coronary intervention in the Canadian health care system? Am Heart J 2006, 151:902-908.

32. Tu JV, Austin PC, Chan BT: Relationship between annual volume of patients treated by admitting physician and mortality after acute myocardial infarction. JAMA 2001, 285:31163122.

33. Ho V, Petersen LA: Estimating cost savings from regionalizing cardiac procedures using hospital discharge data. Cost Eff Resour Alloc 2007, 5:7.

34. Gutierrez B, Culler SD, Freund DA: Does hospital procedurespecific volume affect treatment costs? A national study of knee replacement surgery. Health Serv Res 1998, 33:489-511.

35. Bardach NS, Olson SJ, Elkins JS, Smith WS, Lawton MT, Johnston SC: Regionalization of treatment for subarachnoid hemorrhage: a cost-utility analysis. Circulation 2004, 109: 2207-2212

36. Strehlow MC, Emond SD, Shapiro NI, Pelletier AJ, Camargo CA, Jr: National study of emergency department visits for sepsis, 1992 to 2001. Ann Emerg Med 2006, 48:326-331.

37. Simpson HK, Clancy M, Goldfrad C, Rowan K: Admissions to intensive care units from emergency departments: a descriptive study. Emerg Med J 2005, 22:423-428.

38. Simpson KR, Knox GE: Adverse perinatal outcomes. Recognizing, understanding \& preventing common accidents. AWHONN Lifelines 2003, 7:224-235.

39. Rubin G, George A, Chinn DJ, Richardson C: Errors in general practice: development of an error classification and pilot study of a method for detecting errors. Qual Saf Health Care 2003, 12:443-447.

40. Preventing infant death and injury during delivery. Sentinel Event Alert 2004, 1-3.
41. MacDonald RD, Banks BA, Morrison M: Epidemiology of adverse events in air medical transport. Acad Emerg Med 2008, 15:923-931.

42. Reeve WG, Runcie CJ, Reidy J, Wallace PG: Current practice in transferring critically ill patients among hospitals in the west of Scotland. BMJ 1990, 300:85-87.

43. Uusaro A, Parviainen I, Takala J, Ruokonen E: Safe long-distance interhospital ground transfer of critically ill patients with acute severe unstable respiratory and circulatory failure. Intensive Care Med 2002, 28:1122-1125.

44. Duke GJ, Green JV: Outcome of critically ill patients undergoing interhospital transfer. Med J Aust 2001, 174:122-125.

45. Dewhurst AT, Farrar D, Walker C, Mason P, Beven P, Goldstone JC: Medical repatriation via fixed-wing air ambulance: a review of patient characteristics and adverse events. Anaesthesia 2001, 56:882-887.

46. Gebremichael M, Borg U, Habashi NM, Cottingham C, Cunsolo L, McCunn M, Reynolds HN: Interhospital transport of the extremely ill patient: the mobile intensive care unit. Crit Care Med 2000, 28:79-85.

47. Ehrenwerth J, Sorbo S, Hackel A: Transport of critically ill adults. Crit Care Med 1986, 14:543-547.

48. Rubenstein DG, Treister NW, Kapoor AS, Mahrer PR: Transfer of acutely ill cardiac patients for definitive care. Demonstrated safety in 755 cases. JAMA 1988, 259:1695-1698.

49. Fan E, MacDonald RD, Adhikari NK, Scales DC, Wax RS, Stewart TE, Ferguson ND: Outcomes of interfacility critical care adult patient transport: a systematic review. Crit Care 2006, 10:R6.

50. Singh JM, MacDonald RD, Bronskill SE, Schull MJ: Interfacility transport of acutely-ill patients: incidence of in-transit critical events [abstract]. Am J Respir Crit Care Med 2007, 175 (Suppl):795

51. Trojanowski J, MacDonald RD: Safe transport of patients with acute coronary syndrome or cardiogenic shock by skilled air medical crews. Prehosp Emerg Care 2009, 13:112.

52. Gillman L, Leslie G, Williams T, Fawcett K, Bell R, McGibbon V: Adverse events experienced while transferring the critically ill patient from the emergency department to the intensive care unit. Emerg Med J 2006, 23:858-861.

53. Szem JW, Hydo L, Fischer E, Kapur S, Klemperer J, Barie PS: High-risk intrahospital transport of critically ill patients: safety and outcome of the necessary 'road trip'. Crit Care Med 1995, 23:1660-1666.

54. Waydhas C: Intrahospital transport of critically ill patients. Crit Care 1999, 3:R83-R89.

55. Osmon S, Harris CB, Dunagan WC, Prentice D, Fraser VJ, Kollef $\mathrm{MH}$ : Reporting of medical errors: an intensive care unit experience. Crit Care Med 2004, 32:727-733.

56. Gillman L, Leslie G, Williams T, Fawcett K, Bell R, McGibbon V: Adverse events experienced while transferring the critically ill patient from the emergency department to the intensive care unit. Emerg Med J 2006, 23:858-861.

57. Szem JW, Hydo L, Fischer E, Kapur S, Klemperer J, Barie PS: High-risk intrahospital transport of critically ill patients: safety and outcome of the necessary 'road trip'. Crit Care Med 1995, 23:1660-1666.

58. Resar RK, Rozich JD, Simmonds T, Haraden CR: A trigger tool to identify adverse events in the intensive care unit. Jt Comm J Qual Patient Saf 2006, 32:585-590.

59. Chacko J, Raju HR, Singh MK, Mishra RC: Critical incidents in a multidisciplinary intensive care unit. Anaesth Intensive Care 2007, 35:382-386.

60. National Transportation Safety Board: Special Investigation Report on Emergency Medical Services Operations. Special Investigation Report NTSB/SIR-06/01. Washington, DC: National Transportation Safety Board; 2006.

61. Holland J, Cooksley DG: Safety of helicopter aeromedical transport in Australia: a retrospective study. Med J Aust 2005, 182:17-19.

62. Thies KC, Sep D, Derksen R: How safe are HEMS-programmes in Germany? A retrospective analysis. Resuscitation 2006, 68: 359-363.

63. Hinkelbein J, Dambier M, Viergutz T, Genzwurker H: A 6-year analysis of German emergency medical services helicopter crashes. J Trauma 2008, 64:204-210.

64. Proudfoot SL, Romano NT, Bobick TG, Moore PH: National Institute for Occupational Safety and Health. Ambulance crash- 
related injuries among Emergency Medical Services workers United States, 1991-2002. MMWR Morb Mortal Wkly Rep 2003, 52:154-156.

65. Maguire BJ, Hunting KL, Smith GS, Levick NR: Occupational fatalities in emergency medical services: a hidden crisis. Ann Emerg Med 2002, 40:625-632.

66. Kahn JM, Asch RJ, Iwashyna TJ, Rubenfeld GD, Angus DC, Asch DA: Perceived barriers to the regionalization of adult critical care: a preliminary qualitative study. BMC Health Serv Res 2008, 8:239.

67. Woodward CA, Shannon HS, Cunningham C, Mclntosh J, Lendrum B, Rosenbloom D, Brown J: The impact of re-engineering and other cost reduction strategies on the staff of a large teaching hospital: a longitudinal study. Med Care 1999, 37: 556-569.

68. Seymour CW, Kahn JM, Schwab CW, Fuchs BD: Adverse events during rotary wing transport of mechanically ventilated patients: a retrospective cohort study. Crit Care 2008, 12:R71.

69. Birkmeyer JD, Finlayson EV, Birkmeyer CM: Volume standards for high-risk surgical procedures: potential benefits of the Leapfrog initiative. Surgery 2001, 130:415-422.

70. Singh JM, Ferguson ND, MacDonald RD, STewart TE, Schull MJ: Ventilation Practices and Critical Events during Transport of Ventilated Patients outside of Hospital: A Retrospective Cohort Study. Prehospital Emergency Care 2007, 13:316.

71. Seymour CW, Kahn JM, Schwab CW, Fuchs BD: Adverse events during rotary wing transport of mechanically ventilated patients: a retrospective cohort study. Crit Care 2008, 12:R71.

72. Barrett B, Way C, McDonald J, Parfrey P: Hospital utilization, efficiency and access to care during and shortly after restructuring acute care in Newfoundland and Labrador. J Health Serv Res Policy 2005, 10:31-37.

73. Curtis B, Gregory D, Parfrey P, Kent G, Jelinski S, Kraft S, O'Reilly $D$, Barrett $B$ : Quality of medical care during and shortly after acute care restructuring in Newfoundland and Labrador. $J$ Health Serv Res Policy 2005, 10:38-47. 